\title{
ERRATUM
}

\section{Genetic studies of 20 Japanese families of dystrophic epidermolysis bullosa}

\author{
Daisuke Sawamura $\cdot$ Maki Goto $\cdot$ Kana Yasukawa $\cdot$ Kazuko Sato-Matsumura $\cdot$ \\ Hideki Nakamura $\cdot$ Kei Ito $\cdot$ Hiroyuki Nakamura $\cdot$ Yuki Tomita $\cdot$ \\ Hiroshi Shimizu
}

Published online: 2 September 2006

(C) The Japan Society of Human Genetics and Springer 2006

\section{Erratum to: J Hum Genet 50(10):543-546 DOI 10.1007/s10038-005-0290-4}

In Table 1 and in Result and discussion section, C2875F should read $\mathrm{C} 2876 \mathrm{~F}$.

The online version of the original article can be found at http://dx.doi.org/10.1007/s10038-005-0290-4.

D. Sawamura $(\bowtie) \cdot$ M. Goto $\cdot$ K. Yasukawa

K. Sato-Matsumura $\cdot$ H. Nakamura $\cdot$ K. Ito

H. Nakamura · Y. Tomita · H. Shimizu

Department of Dermatology,

Hokkaido University Graduate School of Medicine,

North 15 West 7, Kita-ku, Sapporo 060-8638, Japan

e-mail: smartdai@med.hokudai.ac.jp 